I have been present at a great many operations for excision of the joints, and I firmly believe that were incision of the joints performed at an early stage in the disease such operations would never be required. Were it for nothing else but the immediate relief of pain produced by incision, I should recommend its adoption.

Les Creax, St. Brelade's, Jersey.

\section{BENEFICIAL USE OF JABORANDI IN CASES OF DIABETES INSIPIDUS OR POLYDIPSIA.}

BY T. LAYCOCK, M.D.,

PROFESSOR OF THE PRACTICE OF PHYSIC AND OF CLINICAL MEDTCINA,

(Reported by J. M. Brown, M.B., and F. Alsop, M.B.)

THe following case of polydipsia was the subject of a clinical lecture by Dr. Laycock during the last winter session, in which he pointed out that the disease in both forms of diabetes and in certain kinds of Bright's disease and dropsy is a neurosis, having its seat in that part of the encephalon which regulates the amount of water in the blood, and having, therefore, both anatomical and functional relations with the sudoriparous glands and the kidneys, and with the appetite for water and the sense of thirst. The pathology and clinical history of both kinds of diabetes were discussed, and the experiments of Claude Bernard and others, as to the production of polyuria, albuminuria, and glycosuria by injury of certain portions of the floor of the fourth ventricle, were alluded to as having a distinct relation to the study of those diseases clinically.

CASE 1. (Reported by J. M. Brown, M.B., class-assistant to Professor Laycock.) -Wm. K-, aged forty, a shoemaker, was admitted to the Edinburgh Royal Infirmary Dec. 24th, 1874. He complained of great thirst, a feeling of pain and heat from the lips to the stomach, profuse urination, and a tendency to pass water frequently; also of dimness of vision.

His previous health had been good until about five months prior to his admission. During these five months he had suffered much from thirst, which was most severe at night and in the morning. He had a bard chancre many years ago, but no other personal indications of syphilis subsequently. His wife had consecutively seven still-born children. As to his social history, he had drunk considerably of whisky, having a bout of drunkenness, lasting for several days, about every three weeks.

Condition on admission. - $\mathrm{He}$ is a slightly-built man, $5 \mathrm{ft} .4 \frac{1}{2}$ in. in height, and weighing 8 st. 4 lb. The integument is hard and dry; temperature $98^{\circ}$. He stated that he did not think he had perspired for five months. The circulatory and pulmonary systems gave normal results, with the exception of a little emphysema of the anterior margins of the lungs. Pulse 92 ; respiration 16 . The tongue somewhat furred, but at the anterior part of the dorsum a small patch is seen, about the size of a threepenny piece, denuded of epithelium, and appearing raw and glietening. The fauces are slightly congested, but quite moist. The appetite is impaired; bowels are regular. Hepatic and splenic dulness normal. He has sometimes to micturate every half-hour. The urine is pale, almost colourless, faintly acid, sp. gr. 1005 ; chlorides; phosphates and urea only in small amount; traces of indican; no sugar or albumen, and no organised or crystalline deposits: in short, it exhibits only the character of a very dilute urine. The testicles are rather small. He states that he has occasional nocturnal emissions, and feels competent for sexual congress. He sleeps well, and is intelligent. Cutaneous sensibility unimpaired. On examining the right eye ophthalmoscopically, the optic nerve was found to be atrophied.

The quantity of urine passed daily during the first week after admission was as follows:-

From 3 P.M. Dec. 24,th till 3 P.Mr. Dec. 25 th, 4,20 oz.

\begin{tabular}{|c|c|c|c|c|c|}
\hline & ", & $25 \mathrm{th}$ & , & & $26 \mathrm{th}, 500 \mathrm{c}$ \\
\hline & " & 26 th & $"$ & , & $27 \mathrm{th}, 300$ \\
\hline
\end{tabular}

From 3 P.M. Dec. 28 th till 3 P.M. Dec. 29 th, 400 oz.

" " $\quad 30$ th " $\quad 30$ " $\quad 30$ th, $330 \mathrm{oz}$.

The patient was ordered a good diet, with two pints of milk daily, and as much ice as he chose to take with his liquids. He also took ten minims of dilute sulphuric acid and ten minims of tincture of opium every four hours. This mixture was continued till Jan. 4th, when the amount of urine in twenty-four hours was $366 \mathrm{oz}$. No good having resulted, twenty grains of iodide of potassium and a quarter of a grain of extract of belladonna were ordered thrice daily. On Jan. 15th it was observed that there was a certain periodicity as to the quantities of urine passed daily, as the following statement shows:-

Jan. 11th to 12 th, $228 \mathrm{oz}$. Jan. 13 th to 14 th, $200 \mathrm{oz}$. " 12 th to 13 th, $272 \mathrm{oz}$. , 14th to $15 \mathrm{th}, 366 \mathrm{oz}$.

Five minims of liq. arsenicalis were given along with the iodide. The patient was desired to take as little fluid as possible. He became very fond of the iced milk and water, and was sometimes observed to drink it ravenously. A warm-water or hot-air bath was sometimes administered, and on one occasion the latter induced a slight cutaneous transpiration, limited, however, to the thoracic and axillary regions. This treatment was continued till Feb. 2nd, the quantity of urine daily passed varying from 256 to $356 \mathrm{oz}$., and the specific gravity from 1005 to 1007 ; chemical characters as befure, except that no indican was discoverable.

During the preceding period he occasionally complained of pain in various parts of his abdomen, back, and under the nipples; these pains were generally relieved by mustard epithems, or friction, sometimes assisted by a carminative. The intestines were on those occasions of ten inflated, and splasbing sounds could be produced by slight manipulation of the abdomen. On Feb. 2nd be was ordered three grains of freshly prepared extract of valerian in pill thrice daily on Feb. 8th, two pills thrice daily ; on Feb. 10th, three pills every four hours. On Feb. 11th he had taken fifteen pills and felt sick and depressed. On the 14th he took no valerian pills, but from the 15 th till the 26 th he took six pills daily. The quantity of urine passed during the period the valerian was administered diminished pretty steadily from 308 oz., sp. gr. 1008, on Feb. 4th and 5 th, to $240 \mathrm{oz}$, sp. gr. 1010, on Feb. 15th and 16th. From this date (the valerian being omitted) till Feb. 26th it steadily increased to $300 \mathrm{oz}$.

On Feb. 26th the patient was still complaining of great thirst, and the skin was dry. Jaborandi was then ordered in the form of infusion of the strength of one drachm of the leaves and twigs to six ounces of water; of this a dessertspoonful was taken every four hours. On Feb. 28th a table. spoonful of the infusion was given every three hours; on March 1st a tablespoonful every two hours; March 4th, two tablespoonfuls every hour. On March 5th the skin of the back, abdomen, and inner aspect of the thighs was found to be perspiring pretty freely. On the 6th (the jaborandi being continued as when last mentioned) the skin of the arms and of the left palm perspired.-15th: The quantity of urine has declined steadily from $300 \mathrm{oz}$. on Feb. 26th to $236 \mathrm{oz}$, on March 14th-31st: The treatment with the jaborandi having been continued, the quantity of urine passed to-day was $180 \mathrm{oz}$. 'The patient has found his mouth uneasy several times, and the amount of the infusion to be taken (varying from one to two taklespoonfuls every hour) is left to bis own sense of comfort or discomfort. His skin is moist, and he declares himself much easier and better in all respects, but still has " some of the old burning feeling in the throat and gullet."-April 2nd: The sense of discomfort in the mouth amounts to-day to pain in the teeth and some slight difficulty in opening the mouth. $\mathrm{He}$ is ordered to take the jaborandi less frequently.

The quantity of urine continued to diminish steadily till the middle of May, when it amounted to $120 \mathrm{oz}$. per diem. His mouth also had become moister. The patient was then, at his own request, discharged.

The measurement of the urine in this case was most carefully conducted by the patient and nurse, and latterly by the patient alone, as he became more interested in the pro. gress of his own case. The measurement of the liquids taken was more difficult, and was at first erroneous for obvious reasons, so that the discrepancy between the amount taken and the amount passed was great; but as the thirst diminished, and the man became in earnest as to the mea- 
surement of the fluids taken and urine passed, there was seldom more than $20 \mathrm{oz}$. difference between the one and the other.

Case 2. (Reported by Fabian Alsop, M.B., resident physician, University Clinical wards.)-William W-, aged thirty-five, a clerk, was admitted to the Royal Infirmary, Edinburgh, under the care of Dr. Laycock, May $29 \mathrm{th}, 1875$. He complains of passing a large quantity of urine, and of a desire to pass it frequently. Also of great thirst, and that he feels inclined to drink a great quantity of water at a time. The water he drinks appears to him to have a sweet taste, especially when it is cold. Patient says that these symptoms commenced nine years ago, during an attack of what the doctor who attended him termed "rheumatic fever." He says that he drank as much water then as be does now. Twelve years ago he had a swelling in the groin after connexion with a woman who would have been likely to communicate infection to him; and five years ago had the venereal disease, for which he was admitted to the infirmary, and, whilst in hospital, had his left testicle removed, and was dismissed cured. Two years after this he was readmitted, and was treated (patient says) for pneumonia. Three months ago a small papule formed at the back of his right thigh, which was not attended to, and which ended in a small ulcer about six weeks ago, and has not yet healed. Ever since his testicle was removed patient has been subject to severe frontal headaches and a feeling of giddiness, which come on him occasionally. His father and mother both died, he states, of consumption; otherwise the family history is satisfactory. He has bad a comfortable home and always been well clotbed, but has been given to sexual excesses and frequently has been " the worse of drink."

Condition on admission.-Patient is somewhat emaciated, and below the average development; height $5 \mathrm{ft}$. 6 in. weight 8 st. $7 \mathrm{lb}$. His muscles are small and rather flabby. He can lie easily in any position, and is not confined to bed. He has a somewhat anæmic aspect, but his expression is natural. Temperature on admission $976^{\circ}$. Skin very dry and rough. Does not perspire at all. No eruptions nor tumours on body. There is a small ulcer, about the size of a florin, on the posterior aspect of the right thigh, with a greyish surface, and which discharges a small quantity of fetid pus; otherwise his limbs are natural. Patient has to micturate frequently, having generally to rise three or four times during the night. Through the day he passes urine, without pain or difficulty, about every two hours, amounting in twenty-four hours to $158 \mathrm{oz}$; of a very light yellow colour, much resembling the colour of hock; sp. gr. 1008, of acid reaction; contains albumen, which occupies about one-eighth of the test-tube when the urine is allowed to stand after boiling; chlorides are abundant in quantity, so also is the urea; no sugar present; no tube-casts to be discovered under the microscope. Patient's tongue is clean. He feels very thirsty, and in order to quench his thirst has to drink a large quantity of water at a time. Has a very pleasant feeling at the back of his throat while he is drink. ing water. His bowels are very irregular in action; some weeks being very constipated, at others loose. Viscera of of abdomen natural. Number of respirations 20 per minute. Has no cough nor breatblessness. Physical examination of lungs natural. Palse 72 per minute; regular in force and rhythm; of fair strength; but slightly compressible. $\mathrm{He}$ does not suffer from any dyspnoea or palpitation. Physical examination of heart quite natural. Patient is very shortsighted. On ophthalmoscopic examination of the fundus of the eye, a large staphyloma posticum is observed on the apparent inner side of the optic disc; the vessels of the retina are also enlarged, and the choroid is found to be atrophied. By direct illumination the fundus is well seen; and when the observer moves his head in one direction, the retinal vessels appear to travel in the opposite direction. Patient is easily exhausted. Sleeps pretty well at night, and would rest better had he not to get up often to pass water. Occasionally he has frontal headache and attacks of giddiness.

Treatment. - The diet was as follows:-Breakfast: Porridge, milk, coffee, and bread. Dinner: Chop or steak, vegetables, broth, and bread. Tea and bread-and-butter in the evening, and milk at night.

June 2nd.- Ordered one tablespoonful of decoction of jaborandi thrice daily.
Progress of case. - The following is a daily table of the amount of urine passed and the amount of fluid taken.

\begin{tabular}{|c|c|c|c|}
\hline Date. & $\begin{array}{l}\text { Amount } \\
\text { of Urine } \\
\text { passed } \\
\text { in } 24 \text { brs. }\end{array}$ & $\begin{array}{l}\text { Amount } \\
\text { of Fluid } \\
\text { drunk } \\
\text { in } 24 \text { hrs }\end{array}$ & Notes. \\
\hline une 1st & $3 \mathrm{oz}$. & $186 \mathrm{oz}$ & \\
\hline , $2 \mathrm{nd}$ & $154 \mathrm{oz} * *$ & $156 \mathrm{oz}$ & $\begin{array}{l}\text { Was up four times to pass urine. } \\
\text { Bowels costive. Half an ounce } \\
\text { of castor oil in the evening. } \\
\text { Jaborandi commenced. }\end{array}$ \\
\hline , 3rd & $150 \mathrm{oz}$ & $156 \mathrm{oz}$ & $\begin{array}{l}\text { Bowels moved freely after the } \\
\text { castor oil. }\end{array}$ \\
\hline , 4 th & $120 \mathrm{oz}$ & $146 \mathrm{oz}$ & $\begin{array}{l}\text { Skin very dry; does not sweat at } \\
\text { all. Dose of jaborandi increased } \\
\text { to two tablespoonfuls. Bowels } \\
\text { moved twice. Was up three } \\
\text { times last night to pass urine. }\end{array}$ \\
\hline , 5th & $140 \mathrm{oz}$ & $146 \mathrm{oz}$ & \\
\hline "6th & $154 \mathrm{oz}$ & $170 \mathrm{oz}$ & $\begin{array}{l}\text { During night sweat a little about } \\
\text { face and hands. }\end{array}$ \\
\hline , 7 th & $148 \mathrm{oz}$ & $186 \mathrm{oz}$ & $\begin{array}{l}\text { Sweat more. Dose of jaborandi } \\
\text { increased to four tablespoonfuls } \\
\text { three times a day. }\end{array}$ \\
\hline „10th & $100 \mathrm{oz} . \dagger$ & $126 \mathrm{oz}$ & $\begin{array}{l}\text { Sweat a great deal about face, but } \\
\text { not on body. }\end{array}$ \\
\hline , 18th & $110 \mathrm{oz}$. & $116 \mathrm{oz}$ & Sweat profusely all over his body. \\
\hline, 25 th & $100 \mathrm{oz}$ & $126 \mathrm{oz}$. & $\begin{array}{l}\text { Saliva for last few days very much } \\
\text { increased. }\end{array}$ \\
\hline July $2 n d$ & $104 \mathrm{oz}$ & 116 oz. & \\
\hline , 8th & $100 \mathrm{oz}$ & 106 oz. & \\
\hline s, 10th & $94 \mathrm{oz}$. & $96 \mathrm{oz}$ & $\begin{array}{l}\text { Sweat very profusely through the } \\
\text { night. Saliva greatly increased. }\end{array}$ \\
\hline s, 19 th & 100 oz. & $106 \mathrm{oz}$ & \\
\hline & 4 & & \\
\hline
\end{tabular}

* Specific gravity 1008 ; albumen 1-8th; chlorides abundant; phosphatic. $\dagger$ Specifie gravity 1010 ; no sugar; albumen 1-6th.

These cases are interesting as showing the use of jaborandi in a disorder well known to be intractable. The action of the drug on the skin (probably through the nerve-centres) was well marked; the salivary glands were less influenced. Edinbargh.

\section{ON THE}

\section{TREATMENT OF HERNIA BY INVERSION.}

Br J. H. THORNTON, M.B., B.A.,

SURGEON-MAJOR, INDIAN MBDICAC SHRVICE, CIVIL SURGBON OF SHAHABAD.

Thrs mode of treatment, though mentioned in most surgical works, has never, so far as I know, been considered on its own merits, but merely as an aid to the taxis and the other measures usually employed in the reduction of hernia. My object in this paper is to draw attention to the efficacy of inversion alone, not only in reducible hernia, but also in many cases where the rupture has become strangulated, and to suggest that a fair trial should be given to a plan of treatment which possesses so many advantages and is attended by so little risk.

The treatment of hernia by inversion consists in placing the patient in such a position as to bring the force of gravity into play to reduce the rupture. This may easily be effected by raising the foot of the patient's bed, and keeping it supported it an angle of $45^{\circ}$. In this posture the intestines naturally gravitate towards the upper part of the abdominal cavity, and gradually draw in the ruptured portion. It is evident, from the nature of the case, that a force acting gradually and equally from within the abdomen must be far safer and more effectual than any pressure applied externally. The use of the taxis, however carefully applied, must almost always involve some bruising of the parts, which would have an injurious effect should the attempts at reduction be unsuccessful and an operation become necessary. Sometimes violent manual pressure is 